\title{
PENSANDO A ADOÇÃO OLHANDO A MATERNAGEM
}

Karine Inae Moreira Peretto ${ }^{1}$, Maria Luísa Louro de Castro Valente ${ }^{2}$

Psicóloga, formada em Psicologia pela UNESP - Assis-SP, bolsista Fapesp. ${ }^{2}$ Professora do Departamento de Psicologia Clínica da UNESP - Assis-SP. E-mail: luisaval@uol.com.br

\section{RESUMO}

Culturalmente, a sociedade atribui à mulher não só a gestação de um filho, mas o cuidado e a responsabilidade da constituição dos primeiros vínculos com o bebê. Desta forma, a pesquisa teve o intuito de estudar como a feminilidade pode estar relacionada ao desejo das mulheres de exercerem a maternagem por meio da adoção; refletir porque algumas mulheres precisam ser mães para se sentirem femininas, enquanto outras preferem abdicar desse papel para assumir outros compromissos sociais; e, compreender o desejo referente à adoção como algo que vai além da feminilidade, o qual perpassa pelo vínculo presente na relação mãe/filho. A coleta do material utilizado na pesquisa foi realizada por meio de levantamento bibliográfico. O método adotado para o desenvolvimento deste trabalho foi o psicanalítico. Pode-se perceber que a mulher ainda não encontrou o seu espaço, fica confusa quanto aos seus desejos e aos desejos que a sociedade espera dela. Pensar na mulher atual é abrir uma diversidade de escolhas, já que ela está redefinindo valores e buscando sua identidade. Atuar no setor econômico e/ou familiar parece não diminuir ou excluir a feminilidade. Aos poucos, cada uma encontrará o seu valor e perceberá que, independentemente da forma como ela se comporta frente às situações, nunca perderá a sua essência, pois ser feminina é estar além de padrões impostos pela sociedade: é olhar a mulher como um todo.

Palavras-chave: Feminilidade; Maternagem; Adoção.

\section{THINKING THE ADOPTION LOOKING TO MATERNITY}

\begin{abstract}
Culturally, the society assigns to women not only the gestation of a child, but the care and responsibility of the constitution of the first links with the baby. Thus, the research aimed to examine how the femininity can be related to the desire of women to exercise maternity through adoption, and to think why some women need to become mothers to feel feminine, while others prefer to abdicate this role to take on other social commitments, and to understand the desire on the adoption as something beyond femininity, which runs through the bond present in the mother/child relationship. The material collection used in the research was conducted through literature. The method adopted for this work development was psychoanalysis. It can be noticed that the woman has not found her space, and is confused about her desires and about the desires that society expects her to have. Thinking about the modern woman is opening a diversity of choices, as she is redefining values and looking for her identity. The fact that the woman acts in economical and/or familiar fields does not seem to decrease or eliminate her femininity. Gradually, each one will find their value and realize that regardless how they behave in these situations, they will never lose their essence, because being feminine is to be beyond the standards imposed by society: is to look at the woman as a whole.
\end{abstract}

Keywords: Adoption; Femininity; Maternity. 


\section{INTRODUÇÃO}

A adoção passa atualmente, ainda de maneira um pouco velada, a ocupar um espaço na sociedade e nas famílias. O modelo familiar presente na sociedade moderna, de acordo com Testoni e Tonelli (2006), está se construindo não apenas baseando-se nos laços sanguíneos, mas também em laços afetivos, religiosos e legais, provocando uma mudança nos papéis sociais representados por cada integrante da família.

São muitos os motivos pelos quais ocorre uma adoção, podendo ser um ato de caridade, como uma forma de preencher a perda de um filho, devido à infertilidade, para ocupar uma falta, ser uma companhia, por motivos religiosos, sociais, dentre outros. No entanto, para que a adoção de fato se constitua é importante que os pretendentes tenham um tempo de preparação e de construção da imagem da criança que se espera, como ocorre também nos nove meses de gestação de um bebê, em que se criam fantasias, expectativas e projetos em relação ao bebê tanto conscientes como inconscientes.

O suporte psicológico com os pais pretendentes a adoção é essencial, independente da motivação que os levaram a tal atitude. Podemos notar a importância deste amparo, quando alguns adotantes culpabilizam as dificuldades apresentadas pela criança a sua vivência anterior à adoção, entretanto, quem são esses pais, como ocorreu a formação desta família e a constituição destes vínculos também são fatores que influenciam no seu comportamento da mesma.

De acordo com Costa e Ferreira (2007), apagar a história de vida, anterior à adoção de uma criança parece ser um desejo comum à quase totalidade dos adotantes, pois na maioria das vezes nesse passado permeiam situações de abandono, rejeição, violência e perdas. No entanto, esta história não pode ser descartada, pois faz parte da constituição da criança, e, conforme afirma Weber (1998), o relacionamento familiar vai ser resultado "[...] da verdadeira capacidade de construir o afeto, com base em trocas e doações" (p. 113).

Um bom relacionamento entre adotantes e adotados, dependerá não só da história de vida da criança como também da história de vida desses pais pretendentes à adoção. Estes precisam estar preparados para lidarem com as angústias, os medos e outros sentimentos que possam surgir após a adoção, por isso é muito importante um amadurecimento dos pretendentes durante todo processo. Deve estar claro aos pais que lugar esta criança vai ocupar em suas vidas.

Para Dolto (1998), a relação mãebebê vai além da herança genética e 
perpassa também pelo vínculo estabelecido entre eles, pois é na cultura e na linguagem que essa relação se estrutura. Weber (1998) considera que todo amor é construído, e que tanto pais adotivos como biológicos, enfrentam dificuldades nos relacionamentos com os filhos, para tanto, uma relação verdadeira suporta qualquer obstáculo. Laços consangüíneos não garantem o amor entre pais e filhos, pois este é construído e conquistado. "A criança escolhe seus pais tanto quanto é escolhida por eles" (DOLTO, 1998, p.97).

Segundo Soifer (1982) o objetivo da família é a defesa da vida e a sua função a de ensino/aprendizagem: nos primeiros anos o ensino cabe aos pais e às crianças corresponde a aprendizagem. A aprendizagem é o método privilegiado de proteção da vida, pois inclui em seus conteúdos a contenção dos impulsos agressivos e destrutivos; "leva a criança num percurso que se inicia no jogo com o próprio corpo até à aprendizagem do mundo do trabalho, cujos primeiros estádios se vão plasmando no brincar com brinquedos, na colaboração em tarefas domésticas e na aprendizagem escolar" (p.29).

Aprender remove ansiedades e a obediência dos filhos é requisito indispensável à sua educação, mas para aprender, o conceito de autoridade é fundamental. Só aprende com quem se respeita e é na relação com os pais que a autoridade do conhecimento se estabelece. Este conceito, o de constituição de um modelo de autoridade é transferido para os professores. Quem ensina o faz porque essa é a sua obrigação, mas através do ato de transmissão de conhecimento exerce autoridade ajudando seus filhos a discernir entre a realidade e a fantasia. "Na base da formação do superego, como se sabe, encontram-se as imagens protetoras dos pais, na sua qualidade de mestres" (p.26), Dolto foi uma terapeuta que conseguiu realizar o seu sonho de criança, "ser uma médica da educação". Poder aliar o conhecimento teórico da psicanálise à compreensão do papel desempenhado pelos pais enquanto modelos, que ao serem transferidos à figura do professor configuram para a criança as figuras da autoridade necessárias ao respeito devido ao educador. Esta transposição possibilita não só o sucesso acadêmico, mas também a possibilidade de doação e da contenção necessárias que se verificam na adoção.

A sociedade impõe valores que acabam interferindo de maneira incisiva nos nossos desejos, desta forma, muitas mulheres se vêem coagidas a terem filhos apenas por questões culturais, não pelo desejo de ser mãe. Badinter (1985) nota que o questionamento e a necessidade de afirmação de que todas as mães devem amar 
incondicionalmente seus filhos, pode estar relacionada à dúvida quanto ao amor de nossa própria mãe.

Assim, para considerarmos de uma maneira adequada o conceito de maternagem, buscamos sua definição no dicionário Houaiss da língua portuguesa (2001), e o diferenciamos do conceito de maternidade. Sendo a maternagem:

[...] esp. das psicoses que busca estabelecer entre terapeuta e paciente, no simbólico e no real, uma relação semelhante à que existiria entre uma "mãe boa" e seu filho o ETIM maternar + -agem, por infl. Do fr. Maternage (1959) 'id', trad. Do ing. Mothering, subst. Ver. Do v. to mother 'tratar maternalmente'[...].

Desta forma, a maternagem é entendida na pesquisa como uma vinculação de qualidade de alguém que tenha a função do cuidar e de uma criança a ser acolhida. Sendo esta relação muito importante, tendo um sentido no vínculo do adulto com essa criança. Diferenciando-se da definição de maternidade:

[...] 1 estado, qualidade de mãe 2 JUR laço de parentesco que une a mãe a seu(s) filho(s) $\mathbf{3}$ (sXIX) estabelecimento hospitalar, público ou privado, clínica ou parte de um hospital que cuida de mulheres no último período de gravidez
* vossa m. tratamento dispensado às religiosas que são madres o ETIM lat.medv. maternitas, Átis 'qualidade de mãe' [...].

O tema proposto nesta pesquisa está sendo muito discutido na atualidade, na medida em que se questionam os papéis desempenhados pelos pais. Pensar a maternagem possibilita então, a compreensão da vinculação mãe/bebê desde o nascimento até a sua vida adulta, e quais questionamentos podem ser compreendidos para um bom equilíbrio e bem-estar deste homem. Em consonância a este conceito está à adoção, ressaltando que o cuidado necessário a uma criança pode ser exercido por qualquer indivíduo que supra essas necessidades, não sendo mais função exclusiva da mãe biológica.

Por estas razões delineamos como objetivo estudar como a feminilidade pode estar relacionada ao desejo das mulheres de exercerem a maternagem por meio da adoção; refletir porque algumas mulheres precisam ser mães para se sentirem femininas, enquanto outras preferem abdicar desse papel para assumir outros compromissos, inclusive sociais; e, compreender o desejo referente à adoção como algo que vai além da feminilidade, o qual perpassa pelo vínculo presente na relação mãe/filho. 
Esta pesquisa pode ser considerada de caráter essencialmente teórico, realizada a partir de um levantamento bibliográfico, adotando uma abordagem qualitativa, com referencial teórico na psicanalítica. A abordagem qualitativa, conforme considera Minayo (2002), possibilita o contato com um universo de significados, crenças, valores, motivos e atitudes, o que corresponde a uma maior profundidade das relações, dos processos, dos fenômenos não se reduzindo apenas a variáveis. Além disso, leva em consideração, o contexto em que os participantes da pesquisa estão inseridos.

Para Pimenta, Damasceno e Valente (2007) este método promove a compreensão de problemas relacionados às pessoas, seus processos mentais e seu contato com a sociedade. Para tanto, uma pesquisa que se utiliza a psicanálise, deve ser pautada na abordagem qualitativa, pois possibilita um contato mais profundo com a singularidade, permitindo a identificação tanto de características individuais como universais. A psicanálise, por sua vez, de acordo com Mezan (2002), pode contribuir para o estudo dos fenômenos humanos, por meio do inconsciente e das forças psíquicas que o abarca e o determina. Para que a sociedade se perpetue é essencial a transmissão da cultura, dos valores, dos costumes e das crenças que perpassam em cada contexto social. Por meio da psicanálise pode-se compreender como cada indivíduo incorpora e introjeta as características próprias de cada grupo. Freud não se restringiu apenas ao setting analítico do consultório, pois possibilitou também a análise de quadros, livros, dentre outros. A psicanálise ultrapassa as quatro paredes do consultório e compreende não só o indivíduo, mas também um coletivo, permitindo o contato com o meio social e cultural.

\section{SER MULHER NA ATUALIDADE}

Culturalmente, segundo Chodorow (2002), a sociedade atribui à mulher não só a gestação de um filho, mas a dedicação, o cuidado e a responsabilidade da constituição dos primeiros vínculos com o bebê. Este papel feminino, ligado à afetividade, aumentou quando ela deixou de ser apenas uma procriadora. Mesmo na sociedade atual, ainda é muito difícil encontrar homens que desempenhem tal papel. A função materna implica em conseqüências na vida da mulher, como a distinção entre os sexos, de masculinidade e feminilidade.

A diferenciação entre o homem e a mulher não se restringe ao aspecto biológico, pois a sociedade determina comportamentos que os caracterizam. À mulher, por exemplo, é atribuída uma maior afetividade, emotividade, carência, passividade e ao homem a racionalidade, a atuação de maneira ativa, dentre outros. Segundo Stoller 
(1982), masculino e feminino refere-se às diferenças anatômicas, o biológico, enquanto que a masculinidade e feminilidade são atreladas à identidade de gênero.

Falar de mulher não é a mesma coisa que falar de feminilidade. A cultura determina valores para homens e mulheres, no entanto, um indivíduo pode apresentar características denominadas femininas como masculinas. Então, o que é preciso para que a mulher se sinta feminina? Apresentar comportamentos que diz respeito somente a ela?

Para a psicanálise, segundo Guimarães (1986), a distinção biológica entre os sexos está apenas na constituição do sujeito, no seu corpo. A sexuação simbólica abrange a linguagem presente no inconsciente de cada um, em que a pulsão de vida e de morte os movimenta. A diferenciação de papéis masculinos e femininos apresenta uma significação no imaginário social e na representação simbólica do sujeito. Ser homem e ser mulher ocorre de diversas maneiras, pois o meio social também apresenta sua contribuição. Deste modo, o aspecto biológico e o social devem estar articulados para a formação da identidade. Esta, por sua vez, se forma ao longo dos anos por meio de processos inconscientes que estão em constante transformação. Assim, a modernidade e a globalização exercem grande influência na sua construção.

O processo de identificação é essencial para a formação da personalidade. Nader (1997) afirma que a família tem um papel determinante, pois passa regras e valores que contribuem para a formação do papel feminino e masculino. Estes valores impostos na cultura colocam a mulher como única capaz de desempenhar a maternagem. Tanto que a maternidade é considerada sinônimo de feminilidade, como se desempenhar essa função torna-se a mulher feminina. Brun (1989) afirma que acontecimentos de ordem sexual na puberdade, experiências eróticas, a maternidade, dentre outras, atualizam a feminilidade da mulher.

A psicanálise, conforme aponta Chodorow (2002), demonstra que a característica de maternação das mulheres ocorre de maneira cíclica, na medida em que a cultura passa de mãe para filha. No relacionamento entre elas já se encontram inseridos, inconscientemente, a capacidade e o desejo de maternar. Uma gravidez possibilita a mulher reviver a desejada relação simbiótica entre mãe-filho e também de reparação à sua própria mãe.

A reprodução dos sentimentos maternos inicia-se logo nos primeiros contatos da mãe com o bebê e é fundamental, pois desperta o psicológico 
para o cuidado infantil, deixa recordações de uma intimidade que nos faz desejar revivê-la. Esse tipo de relação, de acordo com Freud (1914), faz com que os pais revivam nos filhos o seu próprio narcisismo e os tornam depositários de desejos que não conseguiram concretizar. Além disso, essa experiência proporciona o alicerce para que a mulher tenha perspectivas em se tornar mãe.

Além da importância dos primeiros contatos e toques entre mãe/bebê, a escolha dos objetos também contribui para a construção da identidade. De acordo com Chodorow (2002), pode-se verificar este processo no complexo edípico pelo qual as crianças de ambos os sexos passam, mesmo que seja de maneira pouco distinta. A menina a princípio descobre que não possui pênis, pensa ser castrada, rejeita sua mãe e a culpa por não ter lhe concedido um. Em seguida, o desejo por um pênis narcísico como um órgão próprio do corpo, faz com que ela volte-se para o pai e encare a mãe como uma rival. Não há um afastamento sem frustração, hostilidade e até mesmo sem desidealização da figura materna. A menina reage desta maneira, segundo Brun (1989), pois ao perceber ser castrada abdica temporariamente a identificação com a mãe e tenta tirar dela o que ela possivelmente tem, o pai.

Este momento de ruptura do vínculo, conforme afirma Brun (1989), faz com que a filha direcione seu desenvolvimento para a feminilidade, tornando-se uma conquista contra a mãe. Este desejo desperta também na menina o anseio, por meio de fantasias, de ter um filho de seu pai, como uma extensão narcísica para compensar a falta do pênis. A entrada da menina no complexo de Édipo ocorre nesta fase, em que transfere para o pai seu desejo. A resolução deste processo ocorre tardiamente e muitas vezes não se conclui inteiramente.

Mezan (1986) enfatiza que o desejo da menina de ter um pênis não se restringe a possuir um órgão, mas sim ao que ele representa. Segundo Guimarães (1986), o falo simboliza uma falta que a menina, no período simbiótico, acredita ser. Quando é rompida esta relação, nota a presença do pai e percebe que não é o falo. A angústia de sua ausência faz com que afaste de sua mãe e busque esta falta no pai, pois só assim pode obtê-lo. Posteriormente, o falo será substituído, simbolicamente, por um filho. A maternidade supre este desejo da mulher, pois possibilita o reparo do seu próprio narcisismo.

O modo como a perda do falo é superada, conforme considera Brun (1989), interfere diretamente na constituição feminina da mulher. De certa forma, a concretização da feminilidade ocorreria devido a um luto, uma renúncia. Paschero 
(2002) acrescenta que com a resolução do Édipo a mulher passa por três lutos sendo: o de um corpo que aprecia de forma narcísica e que não tem um pênis; a paixão por um homem que não se refere ao pai; e, do filho que teve que não é de seu pai.

A castração representa um momento decisivo para a menina, de acordo com Freud (1931), pois pode direcionar o seu desenvolvimento para três caminhos, sendo: um que conduz à neurose ou inibição sexual; outro que desenvolve um complexo de masculinidade; e, por fim, à feminilidade. No primeiro percurso, a menina renuncia o prazer propiciado pela masturbação do clitóris, rejeita o amor que sente pela mãe e normalmente reprime grande parte de suas pulsões sexuais. No segundo caminho, ela apega-se a atividade clitoriana e esconde-se na identificação com seu pai ou sua mãe fálica. A menina se apega à esperança de que algum dia obterá um pênis; essa espera pode se tornar um objetivo de vida e uma enfatização da sua masculinidade. Por fim, no último desenvolvimento a menina substitui a mãe por seu pai, o desejo do pênis por um bebê e troca sua zona erógena fonte de prazer.

A construção da feminilidade pode ser observada na menina no período da infância, nas brincadeiras de maquiagem, de vestir e de agir como sua mãe. Este comportamento é uma forma dela tentar entender o que é ser mãe. Nas brincadeiras de boneca realizadas na fase fálica, o brinquedo não é um representante da feminilidade. Conforme afirma Freud (1933), ele serve como um intermediário para a identificação da menina com a mãe. Ela atua como sendo a mãe e a boneca é ela simbolicamente. Só quando deseja um pênis é que a boneca-bebê se torna um desejo feminino. Assim, este sentimento decorre tanto da inveja do pênis como das relações primárias com a mãe.

É por meio deste processo de identificação em consonância com a introjeção que os valores sociais são transmitidos. A personalidade feminina é formada desde as relações mais primitivas, pois se espera que o primeiro vínculo seja estabelecido com a mãe. A sociedade confere à mulher o papel de reprodutora e também o de maternagem. Os laços emocionais estabelecidos entre mãe-filho são considerados muito importantes, principalmente pela Psicologia e Sociologia, para que a criança tenha um bom desenvolvimento.

Para Chodorow (2002), a maternação tem base psicológica e é construída ao longo do tempo através das relações estabelecidas com os objetos escolhidos. As primeiras relações entre pais e filhos são recriadas inconscientemente ao longo do tempo, principalmente aquelas que 
não foram elaboradas. Essas relações primárias também vão se modificando de acordo com cada período histórico.

A partir destas considerações, para compreendermos a evolução e as transformações destas relações entre pais e filhos, é importante entrarmos em contato com a história da constituição familiar. Para tanto, é essencial resgatar o conceito de infância que apresenta a sua modificação ao longo dos anos na história da arte e na iconografia.

Por volta dos séculos X-XI, segundo Ariès (1981), a infância era compreendida como um período de transição, em que as crianças eram caracterizadas como adultos em miniatura. Não diferenciavam suas vestimentas e estavam sempre na companhia dos adultos no quotidiano. As brincadeiras voltadas para a criança estavam presentes apenas até por volta dos quatro anos de idade, posterior a este período, adulto e criança se misturavam e compartilhavam as brincadeiras.

Os cuidados da criança, a princípio, eram destinados as amas-de-leite que contemplavam várias crianças ao mesmo tempo, tendo como conseqüência altos índices de mortalidade infantil. $\mathrm{O}$ distanciamento da mãe para com o filho não era decorrente somente do seu desinteresse, mas perpassavam pelas relações, valores, questões econômicas e políticas presentes neste período. Já o conhecimento, as experiências e os valores eram transmitidos pelos mestres, dificultando a construção de uma relação sentimental entre pais e filhos.

A família sofreu uma profunda mudança, de acordo com Ariès (1981), quando apresentou outra atitude frente à criança. Como podemos notar no século XIX, o deslocamento das amas-de-leite de suas casas para morar com as famílias, pois essas não queriam mais se separar dos filhos. Com a transformação desses valores, surge uma preocupação com o amparo empregado ao filho e com a diminuição das taxas de mortalidade. Não bastava mais dar a luz, a maternidade requeria uma doação para com o outro de cuidado, proteção e afeto. Ao longo dos anos, o cuidado com os filhos se tornou responsabilidade da mãe. A justificativa para tal atitude foi de que a criança não era bem tratada pelas amas, como poderia ser por ela, já que esta estaria presente em sua vida em tempo integral.

Essa nova concepção de família voltada para si, preocupada com a moral e com o privado, modifica também a sua dinâmica. Assim, por meio da história social da família discutida acima, podemos ter mais clareza a respeito do papel da mulher na sociedade, já que é na família que vivemos os acontecimentos mais importantes.

Historicamente, de acordo com Nader (1997), a vida da mulher esteve 
conectada à família. A construção de sua identidade restringia-se no aprendizado do modo como administrar o lar, respeitar o marido e da maternidade. Não lhe era permitido que tivesse desejos e vontades, pois tradicionalmente ocupavam um lugar de inferioridade na dinâmica familiar. Desta forma, a educação não a preparava para administrar sua própria vida.

O recolhimento foi a única alternativa para as mulheres até o século XIX. As poucas vezes em que saiam do lar eram para participar de eventos sociais ligados à religião. Elas eram orientadas desde pequenas, de acordo com Nader (1997), ao ensino educativo-religioso como uma forma de preservar sua honra. Tanto os positivistas como os católicos defendiam que as mulheres deveriam manter-se virgens até o casamento. Depois do mesmo precisavam se preocupar apenas em procriar e cuidar dos filhos. Este papel feminino encontra-se de maneira implícita no Código Civil Brasileiro de 1917, em que atribuía à mulher a obediência ao marido e a permanecer junto à sua família.

A conquista por um espaço da mulher na sociedade surge há algumas décadas, já que 0 investimento no desenvolvimento intelectual feminino era mínimo, conforme Blum (1982), pois neste contexto econômico era interessante que sua preparação estivesse focada apenas no casamento. À medida que foi necessária a sua mão-de-obra é que foram abertas as portas para o mercado de trabalho. Aos poucos foram conquistando espaços, se qualificando, perceberam seus potenciais e a possibilidade de obtenção da satisfação de outra forma.

Um dos principais motivos para a emancipação feminina, segundo Alves (2003), foi decorrente dos acontecimentos históricos como o desenvolvimento industrial, avanço dos meios de comunicação e o progresso científico. Desta forma, inseriram a mulher no mercado de trabalho ampliando seu universo não apenas doméstico, mas também social.

A abertura do mercado de trabalho para as mulheres, conforme Moraes (2003), a princípio referiu-se a funções femininas. Podemos notar tal afirmação nas atividades realizadas como de telefonista, funcionária do comércio, professora, enfermeira, dentre outras. Além disso, havia uma disparidade no salário de homens e mulheres, ainda hoje, é possível notar um maior rendimento masculino.

A mulher precisou romper muitas barreiras para conquistar um maior espaço no setor econômico e sustentar uma dupla jornada de trabalho. Ela precisa se preocupar em cuidar do lar, ser mãe, ser esposa e também de ter um tempo para si mesma. Todas as mulheres, independente da classe 
social, de alguma forma, perpassam por estes papéis. Viver num mundo globalizado que preza o lucro, exigem das mulheres, empenho, dedicação e a superação de muitos preconceitos presentes na sociedade em que vivem.

O trabalho é associado à fonte de prazer, realização, conquistas e de construção de si mesma. Passam a administrar e gerir não apenas o lar, mas também o mundo profissional. Conquistam cargos importantes e de tomada de decisão, construindo novos papéis sociais. Apesar de o sexo feminino estar presente de maneira assídua no setor econômico, o acesso aos cargos de poder ainda é muito restrito. Este contexto a força demonstrar cotidianamente que é capaz de conquistar posições dentro da organização, hoje ocupada na maior parte pelos homens.

Para se emanciparem e buscarem a igualdade, as mulheres adquiriram características masculinas, como se esta identificação fosse o passo para a liberdade, para a aceitação. No setor empresarial são apreciados nos grandes executivos comportamentos ligados a razão, o planejamento, a lógica e dispensam emoções, intuições e sensibilidade. O mercado é irredutível e espera que a mulher separe todos esses sentimentos no local de trabalho. Uma figura feminina ideal, segundo Lobos (2002), não permite instabilidade emocional, passividade e cautela excessiva, mas $\operatorname{sim}$ a objetividade, rapidez e foco, permeado por uma sensibilidade. Este processo muitas vezes, é sentido por elas como uma "exigência" do setor econômico atual.

Antes, de acordo com Badinter (2005), temia-se um gênero único, o masculino. No entanto, hoje se observa a busca das mulheres pela identificação com a figura masculina, como se para conquistar um espaço no meio social fosse preciso apresentar comportamentos iguais aos deles. As mulheres virilizadas estão perdendo os valores e a liberdade adquirida ao longo de muitos anos. A opção da mulher pela satisfação por meio do desenvolvimento profissional pode significar abdicação de sua feminilidade?

O contexto capitalista e toda esta mudança de perspectiva de vida da mulher forçam uma redefinição das relações. Muitas delas não têm claro o que as torna femininas, ao mesmo tempo em que a sociedade preza a sua modernidade, defende também o seu recato e conservadorismo. Conforme Emidio (2008), ser mulher é viver o percurso construído historicamente, desfrutar das conquistas e seguir na construção de uma identidade em constante constituição e transformação. Todas estas mudanças ocorrem por meio de um processo, no qual valores estão conectados aos papéis. E hoje, 
podemos pensar na constituição da feminilidade separada da maternidade, pois elas possuem a oportunidade de escolha e dentre elas está o de não ser mãe.

Quando uma mulher relata que não deseja ter filhos é vista com certa desaprovação pela sociedade. Como se ela não estivesse cumprindo seu papel social e não correspondendo, segundo Emidio (2008), - princípio pregado pela psicanálise freudiana de que é por meio da maternidade que a mulher torna-se feminina.

É preciso pensar a psicanálise em consonância ao contexto sócio-histórico que estamos inseridos. Em cada período os valores são revistos e modificados, sendo importante, atentarmos a este fato, pois ao delinearmos o papel feminino é essencial ilustramos o momento histórico. Freud (1933) acrescenta que a psicanálise não se atenta em descrever o que é ser mulher, mas sim como ela se constitui. Se antes buscavam satisfação e eram valorizadas pela maternidade, hoje o campo econômico passa a ser uma opção para isso. Há novas formas de satisfação e possibilidades para a obtenção do falo que não seja pela via da maternidade?

Atualmente, já é conferida a mulher o reconhecimento do seu papel social independente de serem mães. A satisfação profissional em alguns casos supre todos os sentimentos, sensações e realizações presentes na maternidade, pois atua como um reparador narcísico. De acordo com Alizade (2002), o falo ao longo do tempo passa para outros significantes que podem ser representados, por exemplo, pelo dinheiro, fama e posições sociais. Há uma busca tanto dos homens como das mulheres por um lugar de destaque e respeito na sociedade. Já em outros casos elas tentam reafirmar sua feminilidade através de atitudes valorizadas na sociedade, por exemplo, a maternidade. Nestas situações a mãe pode encontrar na criança sua identidade e até mesmo um motivo para viver.

Tendo como base toda a discussão delineada acima a respeito da construção da mulher desde o seu nascimento até a sua constituição enquanto atuante na sociedade, seja por meio da maternidade ou do seu desenvolvimento profissional, podemos fazer algumas reflexões. A diferença anatômica revela apenas a distinção biológica entre homens e mulheres, não a formação de uma feminilidade e masculinidade. A construção de tal formação é resultado da história de cada família e dos valores sociais que são passados ciclicamente de pais para filhos. 0 modo como cada um constitui sua subjetividade depende de todos estes fatores.

O contexto histórico está em constante transformação e, 
conseqüentemente,

os

papéis

desempenhados por cada um. A mulher na atualidade está redefinindo valores e buscando sua identidade. Atuar no setor econômico e familiar ou se restringir a alguns destes campos parece não diminuir ou excluir a feminilidade da mulher. Portanto, ser feminina é estar além de padrões impostos pela sociedade é olhar a mulher como um todo.

\section{DESEJOS DA MATERNAGEM}

Apesar dos diversos caminhos que a mulher pode escolher, a opção pela maternidade ainda é muito forte, mas em algumas situações esse desejo pode não ser realizado. Nestes casos, a adoção pode propiciar sua concretização e, segundo Maldonado (2001), na maior parte das ocasiões a busca por tal caminho é devido à dificuldade ou impossibilidade de uma gravidez, acompanhada de anos de tratamento, espera, frustrações e sentimentos de culpa.

A oportunidade da adoção desperta um sentimento de esperança não só nos pais como nas crianças que são abandonadas, pois famílias que as acolhem evitam que muitas delas passem por situações de maustratos, abusos, agressões, infanticídio, dentre outros. As diversas situações de negligência de pais para com seus filhos biológicos demonstram que uma relação de afeto e amor não depende dos laços sanguíneos. "As histórias de adoção são, portanto, histórias de busca, de encontros (...)" (MALDONADO, 2001, p.48).

É possível construir vínculos afetivos muitas vezes mais intensos e fortes numa relação de adoção, do que em uma baseada na consangüinidade. No entanto, para que uma adoção seja bem sucedida o desejo de ser mãe ou pai deve estar presente, sendo essencial que haja na família a capacidade de compreensão, disponibilidade e doação para com o outro. É importante esta preocupação, pois a adoção em alguns casos demonstra a imperfeição e incompletude do indivíduo.

A adoção é vestida socialmente de muito preconceito, pois ainda há uma valorização familiar baseada nos laços sanguíneos. Aceitar uma criança com uma origem desconhecida é muito difícil, tanto para os adotantes como para os seus familiares. Parece que os laços biológicos trazem uma segurança quanto ao futuro do filho, as situações tornam-se compreensivas, pois independente do que ele faça tem o "mesmo sangue".

A realidade vivida pelas crianças a espera da adoção é de uma sociedade que sente medo e insegurança em relação a eles, devido à incerteza da sua origem e consequentemente do seu futuro. No entanto, confiar que o filho, por ser biológico, não apresentará problemas é tão 
errôneo quanto despejar na origem da criança adotiva toda a culpa pelos problemas que possam surgir.

Outro fator que assombra os pais que pretendem adotar é se serão aceitos e amados pelos filhos adotivos. Eles temem 0 significado da relação que a criança teve com os pais biológicos, assim, é comum os adotantes fantasiarem que se a criança buscar informações sobre sua origem deixará de reconhecê-los como pais e de amá-los.

Por outro lado, a criança também se sente insegura quanto a sua aceitação na família adotiva. Em algumas situações, ela testa os pais para sentir se, independente do que façam, não será abandonada novamente. Algumas crianças, por sua vez, fazem de tudo para agradá-los e para isso reprimem ou omitem parte da sua personalidade.

A expectativa sobre uma criança a ser adotada e sobre os pais que elas aguardam é grande, o que leva a estes comportamentos. Para Winnicott (1989), existem dois tipos de self, um que é socializado e outro pessoal que só se revela na intimidade. O self só se separa do ambiente, quando o bebê tem maturidade para perceber que ele e os objetos são distintos. Quando a criança se comporta com o intuito apenas de agradar os pais e de ser o que eles esperam dela, está exercendo o falso self. É muito preocupante quando ela utiliza de uma fachada como um mecanismo de defesa, pois é como se não fosse boa o bastante diante das fantasias dos pais. Assim, todos os sentimentos, as fantasias e as sensações devem ser elaborados para que a adoção ocorra da forma mais adequada possível e com isso não causar maior sofrimento para ambas as partes.

Um processo de adoção, segundo Weber (2001), deve ter o tempo necessário para que os pais possam se preparar e construir um afeto com aquela criança como ocorre durante os nove meses de gestação. Precisam ser elaborados sentimentos quanto à motivação, os preconceitos e situações como a infertilidade. Desta forma, é indispensável compreendermos os diversos aspectos que perpassam na adoção.

Uma medida já adotada para melhorar o processo adotivo ocorreu em 15 de julho de 2009 com a aprovação do Projeto de Lei do Senado no 314, de 2004 (Projeto de Lei no 6.222-B, de 2005, na Câmara dos Deputados), que estabelece uma Lei Nacional de Adoção. Uma das propostas presentes neste projeto tem $\mathrm{o}$ intuito de reduzir $\mathrm{o}$ tempo da criança nas instituições, pois os postulantes preferem, predominantemente, menina, recém-nascida e branca.

Com dois anos de idade a adoção já é considerada tardia, com isso, a aceleração das ações pode aumentar as chances de uma adoção. Entretanto, um fator que nos faz 
refletir é a precipitação, pois, em alguns casos, tem como conseqüência a devolução da criança. O período de convivência, de acordo com Guimarães (2005), é um momento crucial para verificar se há uma adaptação entre a criança e os postulantes a adoção. Toda etapa deve ser concluída com cuidado, para tentar não expor e preservar a criança.

A burocracia precisa ser simplificada para uma maior agilidade no processo e com isso possibilitar um ambiente acolhedor, protetor e que possibilite um desenvolvimento saudável do adotante. Porém, os pretendentes necessitam ter clareza das suas intenções para que a criança não seja prejudicada.

O processo adotivo precisa ser realizado com cautela, pois toda adoção implica em uma situação de abandono, independente do motivo pela qual ocorreu. Essa situação por si só deixa marcas, por isso o cuidado, como já discutido acima, deve ser efetivo. Em geral, de acordo com Guimarães (2005), os casos de guarda resumem-se a situações de abandono, pais desaparecidos ou sem nenhuma condição econômica de manter os filhos. No entanto, conforme afirma Levinzon (2000), esses sentimentos de abandono e rejeição também são vividos pelos filhos biológicos que possuem pais extremamente problemáticos.
A princípio, quando se pensa em adoção, o olhar volta-se para as crianças, deixando de lado as mães e as razões pelas quais tomam tal atitude. Motta (2001) faz uma discussão importante a esse respeito no livro Mães abandonadas: a entrega de um filho em adoção. Segundo a autora, as motivações que levam a entrega de um filho à adoção perpassam pela dificuldade de criálo, a ausência de apoio, a pressão familiar, pela rejeição a ele ou, até mesmo, uma frustração quanto ao sentimento materno.

Essas mulheres são sempre julgadas e apontadas como frias, insensíveis, irresponsáveis, dentre outras características, mas nem sempre o melhor ambiente para o desenvolvimento de uma criança é ao lado de sua provedora, já que a consangüinidade não é garantia de amor. Além disso, pouco se discute sobre o sofrimento que passam essas mulheres e o quanto ele influi em suas vidas. De acordo com Motta (2001), algumas delas tentam preencher o vazio da entrega do filho apresentando sucessivas gestações como uma compensação da culpa, porém o que conseguem é aumentar o sofrimento. O luto mal elaborado gera dor e pode acarretar num problema pessoal e social.

A responsabilidade pela reação destas mulheres não deve ser direcionada a um único aspecto sendo biológico, social, cultural ou psíquico, mas sim no seu conjunto. O que determina o sentimento 
materno é resultado de todos esses fatores, já que a mulher não é a única capaz de exercer a maternagem. Gerar um filho, não é o mesmo que ser mãe, no entanto, algumas mulheres confundem tal desejo.

Se antes a função materna era considerada inata nas mulheres, hoje, compreendemos que é construída desde o nascimento, perpassando a infância, o ambiente em que vive e a educação recebida. Assim, numa situação em que a mãe abandona o seu filho, não querer desempenhar tal papel, pode significar que ser mãe não é garantia de amor.

Muitas mulheres deixam os filhos em lugares inadequados e que podem trazer risco à vida da criança, de acordo com Motta (2001), por vergonha e por medo de serem julgadas. Com isso, quem mais se prejudica é a criança, na medida em que ela não pode ser direcionada para adoção enquanto a justiça não obtiver informações dos familiares. Esta medida leva tempo e diminui a oportunidade da criança de ser integrada a uma nova família.

Após a entrega da criança, segundo a autora considerada, a mulher acredita que tudo ficará no passado e que poderá continuar seu caminho como se nada tivesse ocorrido. Contudo, não é essa a realidade que se observa, normalmente, esse contexto é permeado por culpa, remorso e tristeza. Todos os sentimentos referentes à perda podem ser considerados parte de um luto. Quando ele não é elaborado, essas mulheres não conseguem estabelecer outras relações, não se sentem merecedoras de serem amadas e, desta forma, negam qualquer possibilidade de serem felizes.

Para tentarmos compreender, ainda que superficialmente, a relação entre as motivações das mulheres que entregam seus filhos para a adoção, as crianças que ficam nesta espera e os postulantes a adoção, precisamos discutir a respeito do vínculo entre mãe/filho. Desta forma, podemos refletir como as mulheres estão vivendo e sentindo atualmente esta relação, já que ser mãe e ser pai é uma função

(...) que mais exige do ser
humano enquanto entrega
pessoal, doação,
desprendimento, muitas
vezes numa relação onde a
troca com o outro se dá em
níveis diferenciados, em
planos afetivos
aparentemente pois o que
desarmônicos, pois pode dar em
uma criança pode
troca, na relação afetiva, é
completamente diferente
daquilo que ela precisa e
recebe, mesmo que
inigualável e imprescindível
(...) (BERTHOUD, 1998, p.
138).

O nascimento, segundo Szejer (1999), causa um abalo na vida do bebê, para se tornar um sujeito depende tanto dele como das figuras paternas. A criança ao 
nascer precisa ser autorizada e ter a sua história reconhecida pelos pais, pelo menos simbolicamente, para que possa se assumir como um ser desejante.

Conforme afirma Berthoud (1998), o vínculo se constrói por meio do sorriso, do toque, do choro, do balbucio, da locomoção, nas trocas, no banho, na alimentação e nas brincadeiras. Cada um desses momentos proporciona prazer tanto para a mãe como para o filho, assim, durante algumas semanas a relação torna-se fortalecida e profunda, marcando a vida de ambos.

A amamentação representa um desses momentos, pois possibilita a mulher uma forma de nutrir o seu filho, de dar continuidade a sua vida garantindo o seu desenvolvimento. $O$ seio tem uma representação importante para a mulher, na medida em que só ela tem a capacidade de amamentá-lo, entretanto, com o avanço tecnológico, principalmente, no setor alimentício o bebê pode ser nutrido por outra pessoa que exerça a função materna. 0 uso da mamadeira, segundo Winnicott (1971), não substitui perfeitamente o aleitamento materno, mas pode torna-se gratificante dependendo da forma como é conduzido. Esse contato entre mãe e filho é essencial para o início de um diálogo e de um entendimento.

Aos poucos, juntos, eles vão se compreendendo comunicação realiza-se através de cada gesto, cheiro, som, toque, apresentando um significado que só eles entendem. A mãe tenta apreender todas as reações e comportamentos do bebê, com o intuito de atender as suas necessidades. Desta forma, “(...) como poderia a mãe aprender a ser mãe de qualquer outro modo que não assumindo a plena responsabilidade?" (WINNICOTT, 1971, p. 26).

Um ambiente favorável possibilitado normalmente pela mãe, segundo Winnicott (1989), facilita o desenvolvimento de tendências herdadas pela criança. Este período ele denominou de "preocupação materna primária" em que ela se adapta a todas as necessidades do bebê propiciando, assim, um "holding" que, para este autor, significa um "segurar" não só físico, mas um ambiente satisfatório, um viver em relação.

No início, de acordo com Winnicott (1960), a mãe identifica-se com o seu bebê e é capaz de se adaptar as suas necessidades. Com isso, o ego do bebê só adquire força e estabilidade devido ao suporte materno. Com o tempo a criança se percebe como uma unidade e entra no estágio do "EU SOU", em que é capaz de conter o estresse e as pressões no seu interior.

Um desenvolvimento saudável do bebê se constitui, de acordo Winnicott (1963), quando a mãe apresenta uma boa relação com a criança e consegue 
permanecer como um ser único na sua vida durante certo tempo. Essa característica de se preocupar está presente no relacionamento entre mãe/bebê, seja ela biológica ou substituta. Este período se conclui quando ambos percebem-se como seres integrais e independentes, assim, o lactente ao longo do desenvolvimento evolui da dependência absoluta para a relativa e por fim a independência. Em consonância a esse processo, o bebê perpassa do princípio do prazer para o princípio da realidade e do auto-erotismo para as relações objetais. Esses estágios são alcançados e sustentados, somente, com um holding suficientemente bom.

As crianças manifestam interesse no "mundo real" por volta dos cinco ou seis anos, no entanto, ela continua relacionandoo com o seu mundo imaginário. Aos poucos, com o auxílio da mãe a criança passa a compreender que o real e o imaginário não são a mesma coisa. Este encontro deve ser dosado pela figura materna, para que o bebê tenha maturidade suficiente para compreendê-lo. As brincadeiras infantis são importantes nesta etapa, pois contribui para a formação da personalidade e de sua capacidade criadora. Além disso, possibilita o contato social e o estabelecimento de relações emocionais.

A menina, principalmente, através das brincadeiras de boneca consegue se identificar com a figura materna. Segundo Winnicott (1971), uma criança que se dedica a esse brincar de cuidar, alimentar, banhar, acariciar, trocar as fraldas da boneca, tenderá a ser uma mãe dedicada. Quando esta tiver o seu bebê já saberá como reproduzir todos os cuidados aprendidos na infância. A relação tão singular entre mãe/filha pode transformar uma mulher em mãe.

O modo como são vividas as relações ao longo da vida depende de como foi vivido e sentido os primeiros vínculos, principalmente, entre mãe e filho. Os desejos para com eles encontram-se presentes desde as fantasias estabelecidas pelos pais a seu respeito, através de imagens e expectativas quanto à criança. No entanto, normalmente, ela não consegue suprir todos esses desejos dos pais, assim, devem primeiramente elaborar o luto do bebê fantasiado para que possam estabelecer um vínculo com o bebê real.

Esses planos são constituídos a partir da história de vida de cada um, desta forma, as relações estabelecidas na vida adulta são resultado de uma evolução dos vínculos construídos na infância. Em uma situação que a criança é entregue para adoção, o convívio com a mãe biológica e, principalmente, com a família substituta são essenciais para a constituição de sua formação. 
Os pais, segundo Freud (1909), são a principal fonte de identificação da criança que, por sua vez, tem como desejo tornar-se igual ao progenitor do mesmo sexo. Ao longo do seu crescimento ela precisa se emancipar da autoridade dos pais mesmo sendo uma etapa dolorosa, este afastamento é necessário e imprescindível. Com o desenvolvimento intelectual, a criança começa a comparar os seus progenitores com outros pais, o que a faz questionar todas as características atribuídas a eles. As crianças criam romances, conforme o autor considerado, através da fantasia que substituem os seus pais por outros com mais qualidades. Podemos dizer que elas não os descartam totalmente, já que apenas acrescem características que gostariam que tivessem. Quando a menina passa a conhecer os papéis que tanto o pai como a mãe possui em uma relação sexual, compreende que não deve ter dúvidas quanto à origem materna.

A família tem um papel fundamental na construção do indivíduo, na medida em que transmite valores, crenças e normas, que influem no seu modo de sentir e de se comportar. Homens e mulheres são produzidos socialmente tanto pelo meio familiar como por meio dos discursos, dos símbolos, das instituições, e dos meios de comunicação.

Ser homem e ser mulher é
Coutinho (1994), da construção de uma trama de significações sociais. Ser mulher refere-se a todos os grupos étnicos e sociais, não existe um padrão para ela, mas sim uma pluralidade de sentidos que as tornam únicas. Cada sexo adquire na cultura suas características por meio do processo de socialização que, por sua vez, os prepara para um papel social considerado adequado. Desta forma, a feminilidade não pode ser considerada um traço natural ou biológico, mas sim resultado de uma construção histórico-social.

Observamos uma modificação nos papéis, conforme afirma Rocha-Coutinho (1994), já que o cuidado com o lar e com os filhos eram tarefas valorizadas nas mulheres pela sociedade. Por anos, foram confinadas no âmbito doméstico obedecendo aos desejos e ordens masculinas, não tinham a abertura para expressar suas vontades, seus desejos e suas insatisfações. Com o tempo, elas descobriram formas de resistência à opressão dos homens, criando modos de obter o controle da própria vida.

Com estas mudanças, segundo a autora considerada, o casamento tem como base novos pressupostos, dentre eles, o amor entre marido/mulher e entre pais/filhos, a igualdade, a liberdade de escolha e a autonomia para a tomada de decisões tanto para os homens como para as mulheres. Esse conseqüência, de acordo com Rocha- 
novo modelo de família nuclear volta-se para si prezando a intimidade e a privacidade.

O contexto familiar, baseado no afeto, se origina do amor materno que, por sua vez, é resultado do discurso higienista. A princípio, há uma valorização do vínculo entre mãe e filho, esse sentimento se expande e abarca toda a família. Uma figura materna considerada "modelo", nesta concepção, deve propiciar uma formação de qualidade ao filho, assim, se responsabiliza pelo cuidado e pela educação oferecida.

Com as Grandes Guerras as mulheres precisaram ocupar, no mercado de trabalho, os empregos vagos pelos homens que estavam nos campos de batalhas. Com o fim da guerra e o regresso dos homens muitas mulheres tiveram que voltar para 0 cuidado com o lar e com a família. Assim, na década de 50 há uma exaltação dos valores sociais tradicionais.

Neste período no Brasil, segundo Bassanezi (2000), as mulheres de classe média eram educadas para serem boas esposas, mães e cuidarem do lar. $\mathrm{O}$ casamento e a constituição familiar era o principal objetivo destas mulheres, como se esta combinação fosse garantia de felicidade. Além disso, era ela quem ficava responsável por manter o marido satisfeito e a união familiar.

Para ser bem vista na sociedade, conforme a autora considerada, a mulher deveria se limitar no cuidado com o ambiente familiar. Ser feminina, neste contexto, estava associado à pureza, passividade, doçura, instinto materno, como se estas características fossem se desenvolvendo naturalmente. Já a masculinidade era sinônimo de força, poder e iniciativa, tanto que ao homem destinava-se a autoridade dentro de casa e o sustento da família. O trabalho feminino, fora do lar, apesar de estar presente neste período ainda era vestido de muito preconceito, pois se argumentava que ao atuar profissionalmente o cuidado com os afazeres domésticos e com o marido eram prejudicados.

Aos 20 anos, a mulher, já deveria estar se preocupando com os preparativos do seu casamento. Depois desta idade, se estivesse solteira, não era vista pela sociedade com bons olhos, por isso que a educação voltada para o casamento iniciavase tão cedo. Almejar outros caminhos, diferente deste, era inaceitável para elas, seu destino já estava traçado antes mesmo de nascer.

Com o intuito de expressar a insatisfação quanto ao seu destino natural, muitas jovens, quebraram as regras morais. As formas de fugir destes padrões eram fumando, utilizando roupas sensuais, desobedecendo aos pais, explorando a sua sexualidade e investindo na carreira profissional. Estes questionamentos 
contribuíram para que o conceito de feminilidade fosse expandido.

Após obter voz dentro do lar, a mulher, estende sua atuação para o meio social, no entanto, não dispensa nenhuma das tarefas consideradas sua responsabilidade. Podemos notar que, em muitas situações, é ela quem não quer perder o controle sobre esse espaço, pois a sociedade ainda valoriza essa imagem feminina da mulher prestativa, útil e que está sempre disposta a cooperar. Quando dividem as atividades podem sentir-se culpadas por precisarem de ajuda.

Além de fazer várias atividades ao mesmo tempo, a mulher deve encontrar espaço para se preocupar com o corpo, com a aparência e, assim, se sentir bonita. Será que é isso o que realmente as mulheres desejam? Em que situações elas se sentem plenas e completas?

Estas questões são importantes, na medida em que mesmo com o avanço feminino no meio social, o seu querer, o seu desejo, ainda está permeado pelos preconceitos, valores e crenças, arraigados na cultura. Depois de todas as lutas feministas, a mulher, não definiu o seu papel e que caminho quer seguir. São tantas as oportunidades de escolha que nenhuma delas deve ser considerada certa ou errada. 0 que se questiona é se a mulher tem clareza do que almeja e de que não nasce destinada a uma função natural.

Com a autonomia feminina e a disponibilidade dos anticoncepcionais, as mulheres, puderam fazer uma separação entre sexualidade e fecundidade. A relação sexual, para a mulher, não tem mais como finalidade a gravidez, pois é livre para obter prazer de outras formas que não por meio da passividade e maternidade. Segundo Langer (1981), mesmo tendo esta separação a mulher percebe, ainda que inconscientemente, uma relação entre o prazer sentido durante o ato sexual com a fantasia de uma gravidez.

A mulher que decide não ser mãe, conforme a autora considerada, pode sentirse realizada, mas para isso precisa encontrar um modo de vida que permita a sublimação dos seus desejos maternos. Para tanto, é essencial que ela aceite suas escolhas e que sejam livres de conflitos.

Com a possibilidade do controle da natalidade, ter filhos é uma opção. Quando se planeja ter um, de acordo com Bauman (2004), são avaliados aspectos como o bemestar e o conforto que podem ser proporcionados, a abdicação da carreira profissional e de outras ambições. A situação econômica familiar tornou-se um fator decisivo na hora de concretizar o desejo de ser pai e mãe. 
Se antes os planos das mulheres tinham um destino definido, fazendo parte dele o casamento e os filhos, hoje, segundo Langer (1981), o nascimento de um filho pode até ser considerado um transtorno. São tantos os caminhos para optar que ela não sabe qual seguir: viver como antigamente ou investir na carreira profissional. As mulheres que se dedicam ao lar, ao marido e aos filhos, enfrentam angústias que até pouco tempo não eram tão presentes. Elas se sentem, muitas vezes, desvalorizadas por não trabalharem fora e terem sua própria renda, como se desperdiçasse os anos dedicados aos estudos. Com o passar do tempo, procuraram ocupar os seus dias com atividades quaisquer para se sentir importante.

A imagem feminina sofreu uma ruptura, conforme afirma Mansur (2003), pois as mulheres passaram a investir nos estudos e na carreira profissional para depois colocarem a maternidade como um dos caminhos a seguir. Por outra perspectiva, algumas mulheres, depois dos 40 anos sentem-se insatisfeitas por não terem constituído uma família e, sobretudo, não terem tido filhos, pois mesmo com esta autonomia feminina ela ainda é a única capaz de dar vida.

Atualmente, segundo Mansur (2003), o que observamos é um adiamento cada vez maior da gestação. A mulher busca, primeiramente, outras formas de satisfação e muitas nem consideram ter um filho como uma opção. Quando ela faz esta escolha, interrompe um vínculo importante com a mãe, distinguindo de sua própria família. Desta forma, excluir a maternidade de sua vida decorre de uma combinação de fatores que fazem parte da sua história.

O investimento na carreira profissional está não só adiando cada vez mais a gestação como diminuindo o número de filhos. As mulheres, de acordo Gasparini (2006), não dão a devida atenção a uma posterior dificuldade para engravidar, parece que se sentem seguras como se frente a qualquer contratempo um procedimento simples resolverá o problema. Elas acreditam que podem vencer as limitações do corpo com a mesma dedicação que destinam a vida profissional.

A capacidade reprodutiva da mulher, a partir de 35 anos, segundo Ribeiro (2004), começa a declinar de maneira mais efetiva e a idade torna-se avançada para ter filhos. Elas passam, então, a buscar mais informações a respeito das novas tecnologias de reprodução assistida e remetem, primeiramente, as dificuldades apenas a conseqüências do envelhecimento do corpo. Entretanto, os fatores que provocam problemas de fecundidade, conforme afirma Moreira et al. (2005), são decorrentes da 
junção tanto dos aspectos orgânicos como psicológicos.

Quando a infertilidade é conseqüência do fator orgânico, de acordo com Braga e Amazonas (2005), as novas tecnologias, aparentemente, parecem solucionar qualquer tipo de problema. A sociedade, num primeiro momento, denomina a mulher como culpada por esta situação. Este discurso acentua ainda mais os estigmas a seu respeito, é como se com esses procedimentos não justificasse tal condição, como se ser infértil fosse uma opção para ela.

O meio social e familiar, segundo Borlot e Trindade (2004), cobram de modo distinto do homem e da mulher, a infertilidade: a ele, associam a idéia de impotência, pois confundem fecundidade com masculinidade e a virilidade; a ela, com a satisfação em exercer a função materna e a feminilidade.

A elaboração de uma infertilidade é difícil, conforme afirma Maldonado (2001), pois como elaborar o luto de algo que não conta com o amparo e a solidariedade, presente normalmente, quando ocorre uma morte. É uma situação pouco discutida, compartilhada e que pode se tornar uma angústia solitária. As dores de não poder conceber um filho no seu ventre, devem ser admitidas e vividas. Ao elaborar todas estas questões, muitas fantasias inconscientes da maternidade se abrandam, podendo diminuir a culpa relacionada a experiências na infância. Apesar de todo esse sofrimento, a busca pela marternagem pode ser decorrente da necessidade da mulher de afirmar sua feminilidade, como se desempenhar esse papel propiciasse tal fato.

Sentir-se mulher independe se ela é mãe ou não, pois a feminilidade encontra-se presente em outros âmbitos da sua vida. No entanto, quando um filho não faz parte dos seus projetos, segundo Mansur (2003), ela precisa moldar sua feminilidade às outras escolhas de vida, sem se basear na maternidade e, para isso, deve enfrentar a visão tradicionalista da sociedade.

Culturalmente, a maternidade ainda é muito valorizada na mulher, já que é a única capaz de dar vida a alguém. Além disso, conforme considera Braga e Amazonas (2005), ter um filho significa para ela ser autorizada pela própria mãe a se tornar mulher. Podemos observar nas clínicas especializadas a sua busca pela gravidez como uma necessidade de se sentir completa e segura.

Após todas essas reflexões podemos nos questionar qual o real desejo das mulheres em serem mães. Segundo Langer (1981), algumas razões são as seguintes:

Deseja um filho porque isto significa recuperar sua própria mãe e também porque the permite identificar-se com ela. Também deseja um filho 
para poder comprovar sua própria fertilidade. $\mathrm{O}$ desejo de um filho pode corresponder ao desejo infantil de presentear uma criança a seu pai. O feto pode representar para 0 seu inconsciente o pênis desejado. (...) Mas, no fundo, o desejo da mulher de dar à luz um filho provém de sua necessidade psicobiológica de desenvolver todas as suas capacidades latentes ( $p$. 198).

Não podemos generalizar um motivo, pois cada uma delas tem a sua história e a sua singularidade que a faz seguir por um caminho ou outro. Pode-se perceber que a mulher ainda não encontrou o seu espaço, fica confusa quanto aos seus desejos e aos desejos que a sociedade espera dela. Portanto, tentar compreender o sentido de cada escolha só cabe a ela.

\section{CONCLUSÕES}

Pensar na feminilidade é olhar na mulher como um todo, seja como mãe, esposa, dona de casa ou profissional, mas para estar completa e plena ela precisa se sentir segura diante de suas escolhas. Neste contexto atual, ela pode optar por investir só na carreira ou na maternidade, no entanto, algumas delas quando escolhem só um desses caminhos sentem-se incompletas e acabam fazendo um pouco de tudo.
Quando o desejo de ser mãe está presente nos seus planos de vida, muitas vezes, ela se depara com alguns obstáculos como a infertilidade. Neste momento, a mulher necessita elaborar os sentimentos de frustração, de fracasso e as angústias geradas para tomar a melhor atitude, seja ir à busca de tratamentos ou da adoção. O principal é ela ter clareza dos seus desejos, pois independente do caminho que escolha eles exigirão maturidade para lidar com as dificuldades que, com certeza, estarão presentes.

\section{REFERÊNCIAS}

ALVES, M. M. P. A primeira feminista das américas. In: GHILARDI-LUCENA, M. I.. (Org.). Representações do feminino. Campinas: Átomo, 2003, p. 15-37.

ALIZADE, A. M. Algumas considerações para demarcar o estudo dos sexos e dos gêneros. In: Cenários femininos: diálogos e controvérsias. Rio de Janeiro: Imago, 2002, p. 59-66.

ARIÈS, P. História social da criança e da família. 2. ed. Rio de Janeiro: Guanabara, 1981.

BADINTER, E. Rumo equivocado: o feminino e alguns destinos. Rio de Janeiro: Civilização Brasileira, 2005.

Um amor conquistado: o mito do amor materno. Tradução Waltensir Dutra. Rio de Janeiro: Nova Fronteira, 1985.

BASSANEZI, C. Mulheres dos anos dourados. In: DEL PRIORE, M. (Org.). História das mulheres no Brasil. São Paulo: Contexto, 2000, p. 607-639. 
BAUMAN, Z. Amor Líquido: sobre a fragilidade das relações humanas. Rio de Janeiro: Jorge Zahar, 2004.

BERTHOUD, C.M.E. Ensaios sobre formação e rompimento de vínculos afetivos. 2.ed. Taubaté: Cabral Editora Universitária, 1998.

BORLOT, A. M. M.; TRINDADE, Z. A. As tecnologias de reprodução assistida e as representações sociais de filho biológico. Estud. psicol. (Natal) [online]. 2004, v..9, n.1, p. 63-70. doi: 10.1590/S1413$294 \times 2004000100008$.

BRAGA, M. da G. R.; AMAZONAS, M. C. L. de A. Família: maternidade e procriação assistida. Psicol. estud.,Maringá , v. 10, n. 1, abr. 2005. Disponível em:

$<$ http://www.scielo.br/scielo.php?script=sci_ arttext\&pid=S1413-

$73722005000100003 \& \operatorname{lng}=e n \& n r m=i s o>$.

Acesso em: 16 ago. 2013.

http://dx.doi.org/10.1590/S1413-

73722005000100003.

BRASIL. Senado Federal. Projeto de Lei no 314, de 2004, de 15 de julho de 2009. Legislação, Brasília, DF, 2009. Disponível em: <http://legis.senado.gov.br/matepdf/62877.pdf >. Acesso em: 29 dez. 2009.

BLUM, H. P. Masoquismo, ideal do ego e psicologia feminina. In: - Psicologia

feminina: uma visão psicanalítica contemporânea. Porto Alegre: Artes Médicas, 1982, p. 114-137.

BRUN, D. Figurações do feminino. São Paulo: Escuta, 1989.

CHODOROW, N. Psicanálise da maternidade: uma crítica a Freud a partir da mulher. 2. ed. Rio de Janeiro: Rosa dos Tempos, 2002.

COSTA, N. R. do A.; FERREIRA, M. C. R. Tornar-se pai e mãe em um processo de adoção tardia. Psicologia: Reflexão e Crítica. Porto Alegre, v.20, n.3, 2007. Disponível em: <http://www.scielo.br/scielo.php?script=sci arttext\&pid=S010279722007000300010\&Ing $=$ en $\& n r m=i s o>$. Acesso em: 01 out. 2008.

DOLTO, F. Destino de crianças: adoção, famílias de acolhimento, trabalho social. Tradução Eduardo Brandão. São Paulo: Martins Fontes, 1998.

EMIDIO, T. S. Diálogos entre feminilidade e maternidade: um estudo sob o olhar da mitologia e psicanálise. 2008. Dissertação (Mestrado)- Faculdade de Ciências e Letras, Universidade Estadual Paulista, Assis, SP.

FREUD, S. (1933) A feminilidade. Edição Standard Brasileira das Obras Completas de Sigmund Freud,. Rio de Janeiro: Imago, 1969. v. 22.

(1931) Sexualidade feminina. Edição Standard Brasileira das Obras Completas de Sigmund Freud. Rio de Janeiro: Imago, 1996. v. 21.

(1914) Sobre o narcisismo: uma introdução. Edição Standard Brasileira das Obras Completas de Sigmund Freud. Rio de Janeiro: Imago, 1996. v.24.

(1909) Romances Familiares. In: Obras psicológicas completas. Edições Standard, vol. IX. Rio de Janeiro: Imago 1980. v.9.

GASPARINI, E. V. R. Experiências com casais inférteis que utilizam a medicina reprodutiva: um estudo psicanalítico. 2006. Tese (Doutorado). Pontifícia Universidade Católica de Campinas, Campinas, SP.

GUIMARÃES, D. G. M. A mulher fala. In: BIRMAN J.; NICÉIAS, C. A.(Orgs.). O Feminino: aproximações. Rio de Janeiro: Campus, 1986.

GUIMARÃES, G. S. A. Adoção, tutela e guarda: conforme o Estatuto da Criança e do Adolescente e o Novo Código Civil. 3. ed. São Paulo: Juarez de Oliveira, 2005. 
HOUAISS, A.; VILLAR, M. de S. Dicionário Houaiss da Língua Portuguesa. Rio de Janeiro: Objetiva, 2001.

LANGER, M. Maternidade e Sexo. Porto Alegre: Artes Médicas, 1981.

LEVINZON, G. K. A criança adotiva na psicoterapia psicanalítica. 2. ed. São Paulo: Escuta, 2000.

LOBOS, J. Mulheres que abrem passagem: e o que os homens têm a ver com isso. São Paulo: J. Lobos, 2002.

MALDONADO, M. T. Os caminhos do coração: pais e filhos adotivos. 5. ed. São Paulo: Saraiva, 2001.

MANSUR, L. H. B. Sem filhos: a mulher singular no plural. São Paulo: Casa do Psicólogo, 2003.

MEZAN, R. Interfaces da psicanálise. São Paulo: Companhia das Letras, 2002.

O escuro dos olhos vacilou como um ouro. In: BIRMAN, J.; NICÉIAS, C. A. (Orgs.). O Feminino: aproximações. Rio de Janeiro: Campus, 1986.

MINAYO, M. C. de S. (Org.) Pesquisa social: teoria, método e criatividade. 21. ed. Petrópolis: Vozes, 2002.

MORAES, T. de. Escritura: caminho para a libertação da mulher. In: GHILARDI-LUCENA, M. I. (Org.). Representações do feminino. Campinas: Átomo, 2003, p. 39-55.

MOREIRA, S. da N. T.; LIMA, J. G. de; SOUSA, M. B. C. de; AZEVEDO, G. D. de. Estresse e função reprodutiva feminina. Rev. Bras.

Saude Mater. Infant. [online]. 2005, v.5, n.1, p. 119-125. doi: 10.1590/S151938292005000100015.
MOTTA, M. A. P. Mães abandonadas: entrega de um filho para adoção. São Paulo: Cortez, 2001.

NADER, M. B. Mulher: do destino biológico ao destino social. Vitória: EDUFES, 1997.

PASCHERO, L. M. de. Contribuições acerca do superego feminino. In: ALIZADE, A. M. (Org.). Cenários femininos: diálogos e controvérsias. Rio de Janeiro: Imago, 2002, p. 81-90.

PIMENTA, D. A. de O.; DAMASCENO, E. R. M.; VALENTE, M. L. C. Escolhendo o método psicanalítico para o trabalho de pesquisa com famílias. In: CONSTANTINO, E. P. (Org.). Percursos da pesquisa qualitativa em psicologia. São Paulo: Arte \& Ciência, 2007. cap. 6 , p.117-143.

RIBEIRO, M. F. da R. Infertilidade e reprodução assistida: desejando filhos na família contemporânea. São Paulo: Casa do Psicólogo, 2004.

ROCHA-COUTINHO, M. L. Tecendo por trás dos panos: a mulher brasileira nas relações familiares. Rio de Janeiro: Rocco, 1994.

SOIFER, R. Psicodinamismos da família com crianças: terapia familiar com técnica de jogo. Petrópolis: Vozes, 1982.

STOLLER, R. J. A feminilidade primária. In: BLUM, H. (Org.). Psicologia feminina: uma visão psicanalítica contemporânea. Porto Alegre: Artes Médicas, 1982, p. 47-61.

SZEJER, M. Palavras para nascer: a escuta psicanalítica na maternidade. São Paulo: Casa do Psicólogo, 1999.

TESTONI, R. J. F.; TONELLI, M. J. F. Permanências e rupturas: sentidos de gênero em mulheres chefes de família. Psicologia \& Sociedade. Porto Alegre, v.18, n.1, 2006. Disponível em: $<$ http://www.scielo.br/scielo.php?script=sci arttext\&pid=S0102-71822 
006000100006\&lng=en\&nrm=iso>. Acesso em: 04 nov. 2008.

WEBER, L. N. D. Aspectos psicológicos da adoção. Curitiba: Juruá, 2001.

Laços de ternura: pesquisa e histórias de adoção. Curitiba: Santa Mônica, 1998.

WINNICOTT, D. W. Tudo começa em casa. São Paulo: Martins Fontes, 1989.

(1963) O desenvolvimento da

capacidade de se preocupar. In: 0 ambiente e os processos de maturação: estudos sobre a teoria do desenvolvimento emocional. Porto Alegre: Artes Médicas, 1983, p. 70-78.

(1960) Teoria do relacionamento paterno-infantil. In: 0 ambiente e os processos de maturação: estudos sobre a teoria do desenvolvimento emocional. Porto Alegre: Artes Médicas, 1983, p. 38-54.

A criança e o seu mundo. 2. ed. Rio de Janeiro: Zahar, 1971.

Recebido para publicação em 11/05/2011

Revisado em 29/11/2012

Aceito em 29/05/2013 